\title{
The potential of mechanism-based bioanalytical tools in ecotoxicological exposure and effect assessment
}

Received: 15 May 2003 / Revised: 17 July 2003 / Accepted: 18 July 2003 / Published online: 16 August 2003

(C) Springer-Verlag 2003

\begin{abstract}
The current challenge to ecotoxicology is to develop tools that allow rapid and cost-efficient detection of those environmental chemicals or their combinations that are responsible for sublethal, chronic toxic effects in exposed organisms. Bioanalytical tools may meet these challenges, particularly if they are mechanism-based. Technically, bioanalytical tools allow rapid and cost-efficient analysis of environmental matrices. Mechanismbased, bioanalytical tools, however, do not only indicate that certain chemicals are there, but - and this is the major advantage of mechanism-based bioanalytical tools (MBBTs) - they indicate that chemicals with a specific mode of toxic action or a specific toxic potential are there. In this way MBBTs bridge exposure and effect assessment and help in a faster identification of the causative agent(s). Several principles of MBBTs, including immunoassays, enzyme inhibition assays, receptor assays and gene induction assays are briefly discussed and their application in processes such as bioassay-directed fractionation is illustrated. The focus of this manuscript is the analytical power of MBBTs in exposure and effect assessment. MBBTs have, however, a much broader potential and can support research on other challenges in ecotoxicology such as mixture effects or multiple effects caused by single pollutants or by various stresses simultaneously.
\end{abstract}

Keywords Bioassay - Biomarker - Immunoassay · Nuclear receptor $\cdot$ Reporter gene $\cdot$ Biosensor

Abbreviations $M B B T$ mechanism-based bioanalytical tool $\cdot R I A$ radioimmunoassay $\cdot E R$ estrogen receptor ·

\footnotetext{
R. I. L. Eggen (凶)

Swiss Federal Institute for Environmental Science and Technology (EAWAG),

Überlandstrasse 133, 8600 Dübendorf, Switzerland

e-mail: eggen@eawag.ch

H. Segner

Centre for Fish and Wildlife Health, University of Bern, Länggass-Strasse 122, 3012 Bern, Switzerland
}

$R R A$ radioreceptor assay $E L R A$ enzyme-linked receptor assay $\cdot$ TIE toxicity identification evaluation

\section{Introduction}

Ecotoxicology is the scientific discipline that is concerned with the impact of pollutants on biota in ecosystems. The technological goal of ecotoxicology is to develop and apply tools for assessing contaminant fate and effects in the biosphere [1]. Central to the achievement of this goal is the availability of exposure and effect assessment tools capable of dealing with the actual and future difficulties in ecotoxicology. Currently, environmental exposure assessment is done mainly by analytical chemistry, aimed at measuring known pollutants in environmental matrices. Effect assessment relies largely on laboratory toxicity tests measuring the effects of single substances or environmental samples on death, growth and (partly) reproduction of single, selected test species.

The ecotoxicological methodology was developed largely during the 1970s and 1980s when environmental systems were challenged by high concentrations of toxicants, and public awareness of environmental pollution was dominated by catastrophic events such as oil spills and overt effects such as mass mortalities. The focus of exposure assessment was on single "priority" pollutants which were selected a priori on the basis of laboratory-derived toxicological data or their production volumes. The focus of effect assessment was on acute exposure to high concentrations, and therefore, relatively crude endpoints such as death or retarded growth were sufficient.

The levels of many contaminants in the environment decreased during the last few decades, and acutely lethal effects are no longer the predominant problem in ecotoxicology. Hence, the ecotoxicological tools that were developed in the past, based on problems in the past, are becoming under pressure, and there is a need to develop approaches and tools that are able to address the actual challenges in environmental contamination. Current difficulties in assessing environmental contamination include [2]: 
i) low doses of contaminants, often with chronic exposure, ii) multiple effects of one and the same compound, iii) mixtures of a wide variety of compounds, including not only industrial chemicals but household chemicals, pharmaceutical compounds or substances arising from lifestyle changes (e.g. musk compounds). This situation leads to new challenges in both exposure and effect assessment. The chemical analytical approach focusing on single, selected toxicants as is still predominantly the case today, is limited in the evaluation of these complex mixtures of known and unknown substances and their metabolites, as being present at mostly low concentrations in surface waters and effluents. Exposure assessment by chemical analysis requires an a priori selection of the compounds to be analysed and thereby may miss toxicologically important substances. In effect assessment, a major problem is that currently available ecotoxicity data are mainly acute lethality data, which provide no information on the possible chronic and sublethal effects of low-dose, long-term exposures. Furthermore, when comparing concentrations of individual, analytically determined toxicants with effect thresholds, the effects of non-analysed toxicants or their metabolites, or for the combinatory effect of mixtures is not accounted for. In this situation, an approach that analyses the presence of environmental contaminants with respect to the biological effects occurring at these concentrations would allow one to assess the actual hazard of the biologically active constituents in the complex mixture. In order to go beyond just analytical detection and to bridge exposure and effect assessment, such a bioanalytical approach has to be mechanism-based. Organisms respond to toxicant stress by a variety of molecular and cellular responses with some of these mechanisms being specific for certain chemical classes or structures, and at the same time being indicative of a specific mode of toxic action [3]. Mechanism-based bioanalytical tools offer several advantages, for instance, they support the systematisation and interspecies extrapolation of chemical effects. This would allow one to address the issue of mixture toxicity, low-dose effects and would help in acquiring generalizable principles. A further advantage of mechanism-based bioanalytical tools is that the biological targets used and validated in the development of these tools could also be utilized for in situ effect assessment on wildlife species. At its best, a bioanalytical method will integrate analytical with toxicological information.

For the purpose of this review, we define mechanismbased bioanalytical tools (MBBTs) as methods that utilize quantifiable and specified detection principles. In this definition, emphasis is on the analytical aspect; the principle for analysis is not a physical one as in chemical analytics, but the detection is based on a defined chemical-biological interaction. Such a definition excludes integrative response parameters (e.g. cytotoxicity), which do not allow the detection of a specific interaction between the analyte and the biological element. Despite the fact that immunoassays do not represent a mode of toxic action and thus are not considered a MBBT, we include immunoassays in this review because they do utilize specific chemical-biological interactions as their analytical principle.
An example illustrating the potential deficits in current exposure and effect assessment is provided by the evaluation of endocrine disruptors. Existing, rather crude ecotoxicological tests procedures do not address this form of toxic impact of environmental substances on biota, and accordingly, environmental substances with endocrine activity have not been included in chemical analytical monitoring programmes until recently. In addition, some of these endocrine-active compounds can induce significant biological effects such as disturbed reproduction at concentrations that are close to current detection limits of chemical analytical techniques. A further complication of exposure and effect assessment of endocrine disruptors comes from the still preliminary observations that mixtures of endocrine-active substances can act additively, an effect that can be not predicted from chemical analytics. This phenomenon of concentration additivity has also been shown to occur with other pharmaceutical compounds, stressing the relevance of this issue [4]. Since many of the hormonally active environmental compounds exert their biological activity through interaction with endogenous hormone receptors, bioanalytical approaches can take advantage of this mechanism and can instrumentalize receptor binding as a means to detect the overall endocrine potency of an environmental sample as it arises from the combined action of all receptor-binding chemicals being present in the sample. The need to develop bioanalytical tools on the basis of sound mechanistic knowledge can also be illustrated with recent developments described in the literature. The identification of more than one estrogen receptor, each having different expression profiles in various tissues, as well as the presence of non-receptormediated signalling pathways clearly show that before developing and using bioanalytical tools it is important to know the underlying mechanisms and the relevant targets in order to be able to understand the biological meaning of the toxicant-induced responses [5].

Interest in novel ecotoxicological methodology arises not only from the limitations of the current exposure and effect assessment tools but also from the need to improve the efficiency, both in terms of cost efficiency and throughput efficiency [6]. Chemical analysis of environmental media for possible hazardous compounds can be exorbitantly expensive and time consuming. Thus, cost-effective and high-throughput methods are required to solve the problem of analysing large numbers of environmental samples [7, 8]. Many bioanalytical methods are microscale assays which is an advantage for high-throughput testing. Further, bioanalytical techniques could reduce costs of conventional analytical chemistry in that they could identify those samples which are positive for certain types of toxic chemicals, they can sort out negative samples, and can direct chemical analysis to the search for the causative chemicals.

\section{Principles of bioanalytical tools}

The development of bioanalytical tools requires sound mechanistic knowledge of the mode of action of contaminants. 
First interactions of pollutants occur at the cellular level. Upon interactions of pollutants in the cell, proteins can be modified, membrane functions get altered or genes get activated in a fine-tuned and coordinated way aimed at maintaining the cellular homeostasis. Both general stress responses and stress-specific responses may occur simultaneously. Detailed examination of the molecular, biochemical, cellular reactions should be made before the relevant and stress-specific molecular processes, key regulatory components and target genes can be identified. This approach and the resulting mechanistic knowledge allow one to study the complex chronic effects, mixture effects and multiple effects. This knowledge also allows one to assess toxic effects at an early stage, even before effects can be seen in whole organisms, and can be used to develop stress-specific and powerful MBBTs.

When trying to categorize the various bioanalytical methods, we have to distinguish between the primary interaction of the chemical with a biological target molecule or target mechanism which forms the basis of the method, and the subsequent transformation of the primary interaction into a quantifiable signal. For instance, the primary chemical-biological interaction may consist of the binding of the chemical as ligand to a biological receptor, and this ligandreceptor interaction may subsequently be quantified as luciferase gene expression in a cell reporter gene bioassay.

In the following discussion, we will present several principles of bioanalytical methods. The intention is not to provide a comprehensive overview of the existing literature or assays, but to exemplify principles and methods and to use these examples to discuss promises and limitations of the assays, particularly with respect to the potential bridging function of MBBTs between exposure and effects assessment.

\section{Immunoassays}

This type of bioanalytical method is not mechanism-based, but takes advantage of the biological ability of antibodies to bind selectively and specifically molecular structures. Thus, immunoassays analyse the presence of specific chemicals but they do not provide information on the biological target of the analytes. Compared to the conventional methods of chemical analytics, the main difference of immunoassays is that they do not use a physical or physicochemical principle for the detection of the analyte, but they rely on antibodies as the detection principle and exploit the ability of these molecules to selectively recognize structural properties of organic molecules. Most immunoassays use monoclonal antibodies produced by hybridoma cells. If antibodies are to be generated against small analytes, it may be necessary to conjugate them to a larger carrier molecule such as bovine serum albumin to render them immunogenic. The site of conjugation and the linkage can influence the specificity and selectivity of the antibody generated.

In immunoassays, the binding event is usually visualized by an auxiliary reaction, in which an immunoreactant or analyte is labelled with an easy measurable substance (e.g. spectrophotometric methods). For immunochemical detection of environmental contaminants, either competitive or non-competitive assays may be used. In the noncompetitive assays, the antibody binds the antigen/analyte, and the resulting antibody-antigen complex is visualized by binding of a second, labelled antibody. The labelling signal produced is directly proportional to the amount of bound analyte. In the competitive immunoassay, the labelled analyte competes with the possible natural analyte for the binding site of the antibody $[6,9,10$, 11]. The first step of the assay is that the well of a microplate is coated with the antibody. The sample matrix containing the analyte is then added to the well, and the immobilized antibody binds the analyte. After washing, the antibody is incubated with labelled analyte which binds to the free antibody binding sites. After rinsing, the amount of labelled and bound analyte is quantified. The amount of analyte in the unknown sample is interpolated from a calibration curve. It is inversely proportional to the amount of labelled analyte. Alternative competitive immunoassay protocols to the one described here have been developed, for instance the use of magnetic particles to separate bound and unbound analyte; however, the principle of the assay remains the same [12].

Various labels can be used to quantify the amount of bound tracer molecule. Many immunoassays use radioactive labels (radioimmunoassays, RIA). These techniques, however, suffers from several shortcomings, including the safety problems inherent with the use of radioactive materials, the cost of instrumentation and the limited half-life of radioisotopes. An alternative labelling technique is the use of enzyme tracers to provide the quantification signal. In this case, an enzyme such as horseradish peroxidase or alkaline phosphatase is conjugated to the tracer molecule, and this enzyme converts a colourless substrate into a coloured or a light-emitting product. The amount of colour or light produced is proportional to the amount of bound tracer molecule. The use of chemiluminescent or fluorescent instead of colorimetric labels can increase the sensitivity of the assays [13]. The advantages of enzyme immunoassays for environmental analytics are the long shelf lives, ease of distribution and suitability for field use [6, 14].

Immunosensors provide an alternative to enzyme-dependent detection systems and rely on electrochemical detection principles. Such immunosensors can be used to quantify the antibody-antigen interaction $[10,11,15,16]$. Electrochemical immunoassays either indicate the antibody-antigen binding directly by measuring changes in charge densities or conductivities of an immobilized antibody layer, or they utilize amperometric or other transducers to quantify the antibody-antigen reaction indirectly [11]. An important advantage of the electrochemical methods is the possibility to develop hand-held devices for on-site measurements.

Immunoassay techniques for environmental contaminants were introduced in the early 1970s [17] and assays for a range of xenobiotics have been developed since, in- 
cluding PCBs [18], pesticides [19], herbicides [20], heavy metals [21], surfactants [22] and environmental estrogens [23]. A number of methods have been established for dioxins and related compounds, since routine monitoring of these compounds is difficult, time consuming and expensive; thus, screening methods that offer improvements in speed, sample throughput and cost are particularly desirable. Therefore, the early immunoassays for environmental contaminants include several dioxin assays [24]. Harrison et al. [25] developed immunoassays against dioxin and related compounds which are now commercially available and which are based on the DD3 monoclonal antibody. These assays have a sensitivity reaching the picogram level and were found to show a response roughly proportional to the toxic potency of the analysed congeners [9, 26]. Dioxin and PCB immunoassays have been successfully applied to the analysis of soil, water, fly ash and biological tissue extracts, although examination of the last of these usually requires rather extensive sample preparation $[26,27,28]$. The correlation between dioxin equivalents derived from chemical analytical measurements or derived from immunoassays were found to be reasonably good. For instance, in a screening study on the dioxins and furans in fly ash from a municipal waste incinerator, Focant et al. reported $r^{2}$-values of 0.84 for the correlation between MS/MS analytical data and immunoassay data [29]. For PCB levels in fish extracts, Zajicek et al. found an $r^{2}$-value of 0.75 [28]. A good correlation $\left(r^{2}=0.92\right)$ between chemical (GC/MS) determinations and immunoassay results was also reported in a study on dioxin compounds in human milk [30].

Immunoassays are intended to complement and not replace conventional analytical techniques. The drawbacks of chemical instrumental analysis - expensive instrumentation, need for relatively large sample volumes (a particular drawback in TIE procedures), need for extensive technical expertise in operation, high costs, relatively slow sample throughput - are overcome by immunoassay methods which are technically simple, cost-effective, and allow rapid throughput of high sample numbers. A further advantage of immunoassays is their potential on-site applicability [11, 14]. With these features, immunoassays can help to identify hot spots, they provide rapid on-site data (what can be crucial in the case of spills), and they essentially facilitate bioassay-directed toxicity identification procedures. It should be considered, however, that production and purification of antibodies with high affinity and specificity is often time consuming. The disadvantages of immunoassays include the possible cross-reactivity of the antibodies to non-target metabolites and matrix elements of environmental samples leading to an overestimation of contaminant levels, and a comparatively low sensitivity $[9,23]$. This low sensitivity of immunoassays implies that they cannot reliably identify those samples that are free of the contaminant.

The immunoassays as described above are just analytical methods, which are focused on a given, pre-selected analyte, and differ to chemical analytics mainly in that a biological molecule instead of a physical principle is used for determination of the analyte. The bioanalytical methods discussed in the following sections detect chemicals on the basis of their ability to interact with a specific biological target molecule or process, that is the analysis is not directed towards a specific, pre-selected analyte but towards the interaction of the analytes with a specific biological target.

\section{Enzyme inhibition assays}

Enzyme inhibition assays such as the cholinesterase inhibition assay [31] or the urease inhibition assay [32], rely on the property of certain chemicals to inhibit the catalytic activity of enzymes. Usually, these assays are performed as microassays with (semi)purified enzyme preparations [32]. An example is provided by the esterase inhibition assay developed by Hamers et al. [31]. The toxicity of organophosphate and carbamate pesticides is based on their ability to block esterases thus inhibiting the hydrolysis of the neurotransmitter acetylcholine by acetylcholine esterase. The esterase inhibition assay employs esterase enzyme prepared from head homogenates of honey bees (Apis mellifera). The enzyme preparation is incubated with dilutions of the test material in 96-well microplates, and the rate of the esterase-catalysed hydrolysis of the substrate $N$-methylindoxyl acetate into the green fluorescent product $N$-methylindoxyl is followed in a fluorescence plate reader. If a test sample contains organophosphates or carbamates, hydrolysis of the substrate $N$-methylindoxyl by the esterase enzyme is competitively inhibited by the pesticides and measurable enzyme activity is decreased compared to controls. Data analysis can be performed by using Michaelis-Menten kinetics for competitive inhibition. To this end, the esterase-inhibiting potency of the sample is quantified as the inhibitor constant $K_{\mathrm{i}}$, which is calculated using Lineweaver-Burk equation.

Frequently, the effect strength measured in a bioanalytical method is expressed as relative potency compared to a reference compound. This approach offers the possibility to compare the biological potency of the sample, as determined in the bioanalytical assay, with the theoretical potency of the sample expected on the basis of chemical analytical determination of individual components. In their esterase inhibition assay, Hamers et al. [31, 33] used dichlorvos as the reference compound, and the esterase inhibiting strength of the sample is converted into dichlorvos equivalent concentrations $\left(C_{\mathrm{DEO}}\right.$, ng dichlorvos equivalents $\left.\mathrm{L}^{-1}\right)$ by dividing the $K_{\mathrm{i}}$-value of dichlorvos by the $K_{\mathrm{i}}$-value of the sample. To express the esterase-inhibiting potency of the sample relative to dichlorvos, the comparison is usually made at the $50 \%$ effect level $\left(\mathrm{EC}_{50}\right)$, and the concentration-response curves of sample and reference substance ideally should be parallel. Then, the concentrations $\left(C_{\mathrm{x}}\right)$ of organophosphate and carbamate pesticides in the same sample are determined by means of chemical analytics, and for each of the chemically analysed pesticides, the $C_{\mathrm{DEQ}}$ is calculated by multiplying the actual concentration of the analyte in the sample, $C_{\mathrm{x}}$, by its esterase-inhibiting 
potency - expressed as concentration leading to $50 \%$ inhibition, $\mathrm{IC}_{50}-$ in relation to the $\mathrm{IC}_{50}$ of dichlorvos. Assuming that the joint toxicity of the esterase-inhibiting pesticides in the sample can be described by concentration additivity, the theoretically expected esterase-inhibiting potency of the whole sample can be estimated by summing up the equivalent concentrations $C_{\mathrm{DEQ}}$ of the individual pesticides in the sample. If the chemically derived esteraseinhibiting potency of the sample is significantly less than the bioanalytically determined value, this would indicate that the sample contains additional esterase-inhibiting chemicals that have been missed in the chemical analysis. If the bioanalytically determined value is comparatively less than the analytically derived one, this could indicate an inhibition of the bioanalytical method (e.g. by matrix effects). This example clearly illustrates how important it can be to use chemical analytics and biologically based analytical tools cooperatively.

\section{Receptor-based assays}

Chemicals belonging to several different structural classes have been identified to induce biological responses through binding and activation of biological receptor proteins (examples in Table 1). Well-known examples of this mode of action are certain dioxins, PCBs, PAHs, indocarbinoles and imidazoles which are ligands of the aryl hydrocarbon receptor (AhR). Another group of chemicals which bind to an endogenous receptor are environmental estrogens. Actually, this structurally diverse group of natural, synthetic or industrial compounds, is defined in terms of their potency to act as ligand of the estrogen receptor (ER). In the case of the ER, the physiological ligand is the endogenous estrogen, $17 \beta$-estradiol (E2), while for the AhR no endogenous ligands are known.

We would like to emphasize that we use the term "receptor" not in the very broad sense as it is often found in the bioanalytical literature (i.e. as any biological structure, be it an antibody, enzyme, protein, cell, or tissue, that utilizes a biochemical mechanism for analyte recognition), but we restrict the use of the term "receptor" to those biological molecules who have the physiological function of binding endogenous signal molecules within the organism and to regulate gene expression [10].

The ability of certain environmental contaminants to bind to a specific biological receptor protein can be uti- lized for bioanalytical purposes. A bioanalytical tool that contains the biological receptor molecule as the sensing element will be able to selectively recognize all those chemicals within a complex sample which are ligands of this receptor. In fact, a variety of assays systems are based on the analytical principle of contaminant-receptor binding. This primary event can then be quantified by a range of different methods, some of which are illustrated below.

The most straightforward approach is the competitive ligand binding assay, usually performed as a radioreceptor assay (RRA). In this method, a solution containing both a cytosolic or nuclear preparation from a receptor-harbouring tissue, and the radiolabelled physiological ligand of the receptor are incubated with the chemical or environmental mixture in question. If the chemical or a compound in the mixture is able to bind to the receptor, they will compete with the labelled ligand for the receptor. After incubation, the free radiolabelled ligand is separated from the receptor-bound ligand and is expressed as the percentage displaced by the competing compound. RRAs have been used for the identification of estrogenic potencies, be it of of individual chemicals, environmental mixtures or tissue extracts [34, 35, 36, 37]. Interspecies extrapolation of RRA data has to be done with caution, since binding affinities of the receptors may differ between species due to possible differences in receptor structure.

An advantage of the RRA is that it can be used with preparations from any species, and that it can be performed rapidly for relatively large sample numbers. The assay does not distinguish between agonists and antagonists, which may not be a disadvantage in a primary screen. Disadvantages are that the RRA cannot detect any event downstream to primary ligand-receptor interaction, and that the receptor molecule usually has to be freshly prepared from tissue homogenates which makes the assay laborious and also introduces some inter-assay variation (methodological variability between individual preparations, individual- or situation-dependent variation among the donor animals or donor tissues, etc) [38]. The use of recombinant receptors may eliminate or diminish these confounding factors.

One application for recombinant receptor molecules is the enzyme-linked receptor assay (ELRA) [39, 40]. The ELRA is a microwell-based receptor binding assay using a receptor produced for instance, in a recombinant yeast expression system. Measurements are carried out in 96well microwell plates. In the ELRA for estrogen receptor

Table 1 Examples of chemicals that belong to different structural classes, inducing biological effects through binding and activation of receptor proteins

\begin{tabular}{lll}
\hline Receptor & Ligands (selection) & \\
\cline { 2 - 3 } & Natural or synthetic & Xenobiotics \\
\hline Aryl hydrocarbon receptor & Aromatic amines, indocarbinoles, PAHs & Dioxins, furans, PCBs, PAHs, imidazoles \\
Estrogen receptor & $17 \beta$-estradiol, 17 $\alpha$-ethynylestradiol, flavonoids, & Octylphenol, nonylphenol, bisphenol A, \\
& genistein & hydroxy-PCBs, phthalates, $o, p$-DDT, \\
Androgen receptor & Testosterone, 11-keto-testosterone, & Vinclozolin, flutamide, $p, p$-DDE \\
& 5-dihydroxytestosterone & \\
\end{tabular}


binding chemicals developed by Seifert et al. [40], initially an estradiol-BSA conjugate is adsorbed to the surface of the microwells. In the second competition step, an estradiol solution of defined concentration is added together with the human estrogen receptor alpha. After the receptor binding reaction, a biotinylated mouse antiestrogen receptor antibody is added. When the luminescent substrate luminol is used as label, a detection limit of $0.02 \mu \mathrm{g} \mathrm{E} 2 \mathrm{~L}^{-1}$ could be achieved [40]. The ELRA approach has proven to be robust and highly suited for the detection of natural and synthetic estrogens and xenoestrogens in field studies.

Another example in which recombinant receptor molecules can be applied in the context of a bioanalytical application is affinity chromatography. In this approach, the receptor molecules are not used for analytical detection this is still done by conventional chemical analytical methods - but the biomolecule is used to enrich the analyte from complex environmental samples. Receptor molecules are immobilized on a separation affinity matrix which is then loaded with the test sample [41]. Subsequent to the "biological extraction", the bound substances are eluted from the column and are subjected to chemical analytics for substance identification.

A promising approach in which active receptor molecules are directly used in a chemical analytical instrument is the analytical detection of specific, non-covalent interactions of ligands with for example nuclear receptors using electrospray ionisation and mass spectrometry [42]. The non-covalent complexes can be studied in the gas or liquid phase; the latter is generally considered to reflect the biological system better.
Gene induction assays

These assays measure the induction and reduction of gene transcription following toxicant exposure. Frequently, the initial step in the gene induction cascade is binding of the foreign molecule to a receptor protein, either membrane bound or intracellular, possibly triggering subsequent signalling steps, and finally leading to a regulated target gene expression. In environmental toxicology, the best-studied examples of chemical binding to endogenous receptors and subsequent gene induction are chemicals that activate AhRregulated and ER-regulated genes (Fig. 1). Binding of either a physiological or xenobiotic ligand to AhR or ER results in a conformational change of the receptor that facilitates binding of the activated receptor to specific DNA sequences (estrogen or dioxin response elements), which in turn results in a modulation of gene transcription. The unbound cytoplasmic receptor is maintained in an inactive conformation through interactions with several associated proteins, such as the chaperone protein HSP (heat shock protein) 70. The binding of the endogenous ligand to the receptor leads to a dissociation of those associated proteins and a conformational change of the receptor protein into the active form. Once activated, the receptors then form either homodimers or heterodimers, may bind additional proteins such as ARNT (arylhydrocarbon receptor nuclear translocator), and are translocated into the nucleus. There the activated receptor complex binds to specific DNA motifs, the so-called response element, which contain the promoter regions for specific genes. Subsequently, the transcription of those genes is initiated. The gene activation can be additionally modulated by tran-
Fig. 1 Principles of nuclear receptor-mediated gene activation

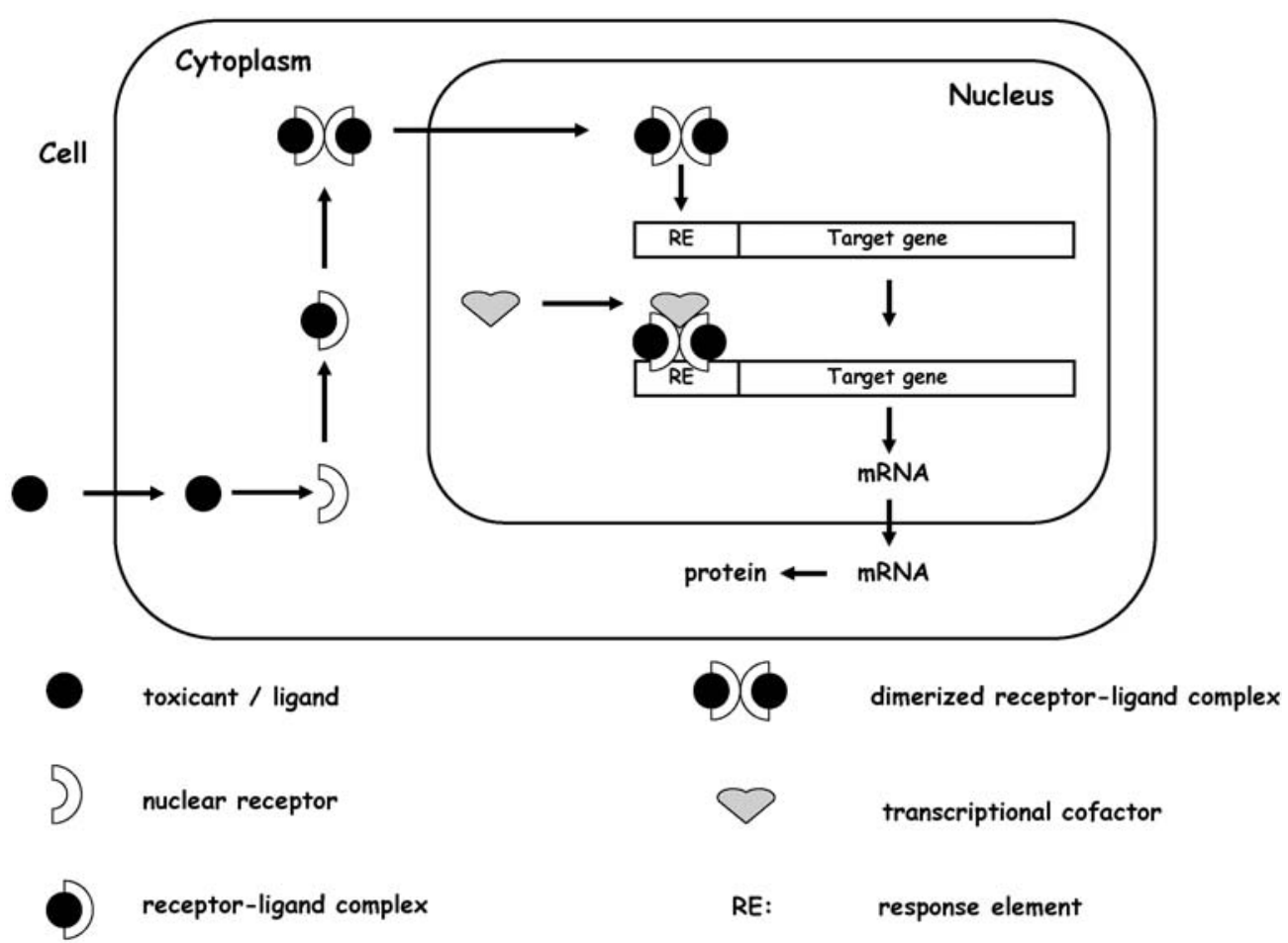


Fig. 2 Principles of reporter gene activation

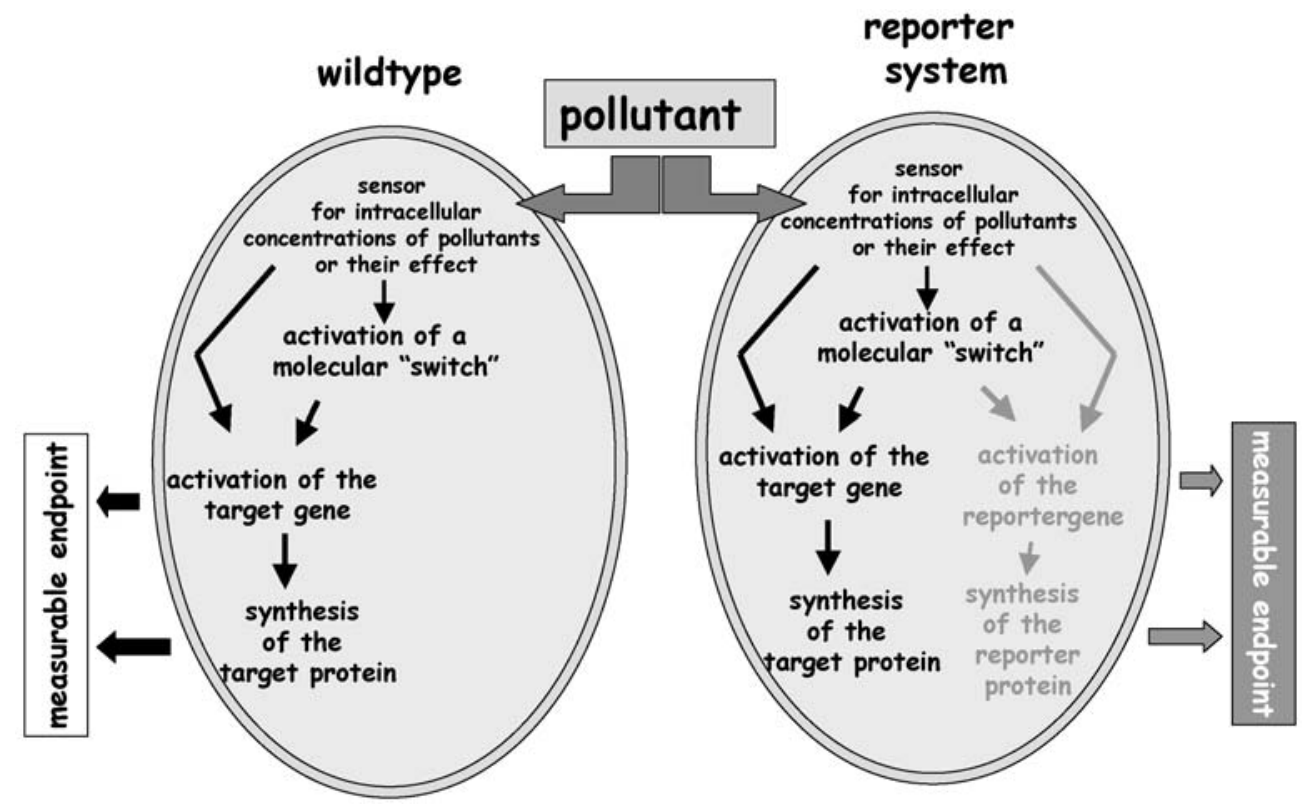

scriptional co-activators which interact with the receptor-DNA complex.

In cell-based assays, either endogenous responses or exogenous reporter systems incorporated into the cell are used to quantify the induction of gene transcription, following exposure of the cell to specific ligands or to mixtures of compounds. The endogenous products of the induced gene in a genetically non-modified ("wildtype") cell can be detected by a variety of techniques, for instance, the mRNA by means of Northern blots or quantitative RT-PCR, the protein by using antibodies in Western blots or ELISA, and protein activity by means of enzymatic assays (Fig. 2). In genetically modified cells, reporter systems are used to assess gene expression [43]. In the reporter assay, the transcription of the endogenous target gene is induced as well as the gene encoding an easier to measure and quantifiable "reporter" enzyme (Fig. 2). The endogenous machinery of the cell translates this product into a fluorescent protein (e.g. GFP, RFP, BFP, YFPgreen/red/blue/yellow fluorescent protein), or into enzymes, such as luciferase, chloramphenicol acetyltransferase, $\beta$-galactosidase or alkaline phosphatase. When substrate is added to the cell culture medium, the enzyme catalyses the light-emitting or colorimetric reaction, which is related to the level of gene induction. The responsiveness of assays can be characterized by maximal fold induction relative to control, slope of the dose-response curve, and detection limit. Genetically engineered cells are reported to exhibit greater sensitivity, dynamic range and selectivity than their corresponding wildtype cells [44, 45].

Gene expression assays have the advantage over receptor binding assays in that they can distinguish between agonists and antagonists. Furthermore, post-translational effects can be observed [38]. Additionally, gene expression assays have some level of integration in that not only receptor binding is analysed, but also the consequence of receptor binding for subsequent gene activation. Depending on the cell system used, disadvantages of the gene induction assays may be that they require specialized equipment and trained staff. This is particularly true when using vertebrate cell lines. Much less difficulties, both in handling, reproducibility and costs, are encountered when yeastbased or bacteria-based assay systems are being used. If cell-based gene induction assays are used, care has to be taken that only non-cytotoxic concentrations of the test agent are applied. A number of reporter assays are based on yeast cells. Their cell walls are difficult to be passed for a range of xenobiotics, what could lead to reduced intracellular accumulation and, consequently, to an underestimation of effective concentrations of the test compounds or samples. Another aspect that has to be considered is the metabolic activity of the cell system, since for a number of toxicants it is not the parent compound but the metabolite which binds to the receptors. For instance, Petit et al. compared the estrogenic effect of 30 chemicals, using a recombinant reporter yeast assay and primary hepatocytes of fish, and found that the response of the two bioanalytical systems differed for more than $30 \%$ of the test substances, probably due to the various metabolic capabilities of the two assay systems [46].

A variety of gene induction assays based mainly on bacterial, yeast, fish and mammalian cells and have been developed since the early 1990s and applied for the testing of a broad range of chemicals and environmental and biological matrices (for recent overviews see refs. [47, 48, 49]). For instance, to measure the dioxin-like activity, recombinant yeast cells, continuous teleostean and rodent cell lines and primary cell cultures from fish, birds and mammals have been used [50, 51, 52, 53, 54, 55, 56]. Differences of the gene induction response among cell systems derived from various species have been reported [53, $54,57,58]$, which may relate to species-dependent ligandbinding affinity, in the expression level and structure of the receptors and their associated proteins, and in the ac- 
tivity of transacting factors [48, 51, 59]. Gene induction assays have also been frequently applied for the screening of environmental samples, biological matrices or biological mimics such as semipermeable membrane devices [36, $60,61,62,63]$ and they have been applied in bioassay-directed fractionation procedures $[64,65]$. To estimate the relative potency of chemical mixtures, a toxicity equivalency approach, as described above for the esterase inhibition assay, can be used [48, 58, 66]. Generally, reported correlations between chemical analyses and gene induction assays range from reasonable to good. For instance, in a recent study on dioxin-like contaminants in food samples, Spearman rank correlation coefficients between 0.67 and 0.73 were observed between chemically determined dioxin equivalents and equivalents determined by means of the CALUX reporter gene assay [67]. More importantly, no false negative results were obtained with the CALUX assay. Similarly, a correlation coefficient of 0.6 has been reported between chemically determined estradiol equivalents in wastewater treatment plant effluents and measured estradiol equivalents using the recombinant yeast estrogen screen [68]. Also, no negative results were found here when using the in vitro reporter gene assay. However, poor correlations between bioanalytical and chemical analytical data have also been shown. For instance, Roy et al. [69] examined dioxin equivalents in soil samples using a CYP1A gene induction assay in the wildtype H4IIE cell line immunoassay and GC/MS. Correlation coefficients were 0.45 between immunoassay and GC/MS, and 0.08 between the gene induction assay and GC/MS. One possible explanation for this poor correlation could be that the assay is inhibited by interfering compounds in the extract [69]. However, since the gene induction assay tended to indicate higher dioxin equivalents than GC/MS, it may also be possible that the GC/MS analysis missed chemicals with dioxin-like activity present in the sample. That chemical analysis searching for a number of pre-selected substances may easily overlook biologically active compounds in an environmental sample is nicely illustrated by a recent study by Brack and Schirmer [70]. These authors performed a bioassay-directed fractionation on a toxic river sediment in order to identify contaminants with dioxin-like activity. As the bioanalytical tool, they used a fish cell line measuring AhR-mediated CYP1A induction. As expected, they found high levels of dioxin equivalents in the more lipophilic fractions, representing classical dioxin-like chemicals such as PCBs and homocyclic PAHs. Unexpectedly, however, they also noticed pronounced dioxin-like activity in the more hydrophilic fractions. These fractions contained heterocyclic O-PAHs and S-PAHs, which obviously are also CYP1A inducers but which are not considered in standard chemical analyses. In such a situation, the biological assay would "overestimate" the dioxin equivalents in the sediment, if the comparison to chemically derived dioxin equivalents would be made only on the basis of analytical determination of the classical CYP1A inducers.

To determine the biological potency of an environmental sample, complete concentration-response curves of the measured gene induction response should be obtained. However, complex extracts of environmental matrices may not result in classical, sigmoidal concentration-response curves, since they can contain cytotoxic substances for instance [48]. Therefore, assays measuring cell viability should be routinely included when testing environmental samples. Furthermore, in order to account for obscured concentration-response relationships in testing of environmental samples, Brack et al. [65] suggested to use fixed effect levels in the lower range of the concentration-response curve for the determination of dioxin equivalents in complex samples, for instance, the $\mathrm{EC}_{15}$ level, instead of using $\mathrm{EC}_{50}$ levels.

Gene induction assays are not necessarily restricted to the use of in vitro cell systems, but can also be applied with intact animals in vivo. This was recently demonstrated by Legler et al. [71]. These authors developed a novel in vivo testing system on estrogenic substances using transgenic zebrafish, Danio rerio. In the transgenic zebrafish, an estrogen binding sequence linked to a luciferase reporter gene was stably introduced. Binding of a substance to the endogenous estrogen receptor and the subsequent activation of the receptor result in luciferase gene induction that is easily measured in tissue lysates. This approach offers vast possibilities in rapid screening for estrogenic exposure, in evaluating tissue-specific effects of chemical exposure under physiological conditions and in investigating toxicokinetic parameters.

\section{Bioassay-directed analysis of environmental samples}

The concept of bioassay-directed analysis of environmental samples is based on the toxicity identification evaluation (TIE) approach developed by the US-EPA [72, 73]. The linkage of effect measurements using bioanalytical tools with chemical analytical procedures has become a valuable tool for the identification of environmental pollutants as the causative agent for observed effects. Principally, fractionated environmental samples are analysed on their effect potential using bioanalytical tools, followed by a chemical analysis of the active fractions. Further fractionation, biological effect measurement and chemical analysis may be repeated until the causative compound can be identified. Advantage of the bioassay-based analysis is that the analysis is not focussed on the measurement of a relatively small selection of chemicals, which may be the wrong (e.g. not the biologically effective) one, but is based on effects to be studied. A further advantage is that a lottery-type selection of the possibly relevant chemical out of the mixture of compounds in an environmental sample, without having sound selection criteria, is avoided. The use of this approach has been demonstrated in various environmental samples such as sediments [74], wastewater effluents $[64,75]$, surface waters [76] and others. Bioanalytical tools used in the bioassay-directed analysis are various, ranging from sub-cellular to whole organisms. Whole organisms such as Daphnia and fish are not so easy to handle and need relatively large sample amounts. 
In addition only descriptive endpoints are measured, such as death or reduced growth, which do not allow one to draw any mechanistic conclusion. The use of smaller organisms has been recognized as being advantageous for several reasons. They can be maintained under much better controlled laboratory conditions. The reproducibility of the results is increased. They react much faster due to shorter life cycles and, extremely importantly, require much smaller sample volumes, thereby saving valuable samples for subsequent chemical analysis. Indeed, luminescent bacteria have been used increasingly [75]. Only very descriptive endpoints are measured in this approach and hence no hints towards the toxic mechanisms underlying the observed effects can be obtained.

We expect major improvement towards the measurement of specific effects by using bioanalytical tools, which have been developed on the basis of mechanistic knowledge of underlying processes. These bioanalytical tools may be antibody-based, receptor-based or gene-induction based as described above. A very elegant, illustrative example is described by Desbrow et al. [64]. These authors used a genetically modified yeast system to identify estrogenic-active compounds acting via the estrogen receptor. By using this bioanalytical tool, the steroid hormones were identified as the major endocrine-active compounds in communal wastewater treatment plant effluents. Such mechanism-based, specific bioanalytical tools, possibly linked with very sensitive molecular detection principles, seem very promising tools in the bioassay-directed approach.

Despite the fact that the concept of bioassay-directed analyses of environmental samples is convincing, the status of its use is still not very well established. This may be due to the general fact that the final identification of a special causative chemical is very time consuming and therefore expensive. A further difficulty is most probably the absence of sufficient bioanalytical tools, which would allow a faster and selective analysis. Bioanalytical tools as we defined them, linked with molecular detection methods, will most probably support the further development of the bioassay-directed analysis.

\section{Conclusions and perspectives}

In this manuscript we have discussed the potential of MBBTs to assess exposure and effect of pollutants, complementary to chemical analytical methods. MBBTs could overcome several of the current problems in ecotoxicological exposure and effects assessment. They allow rapid and costefficient analysis, allow a mechanism-oriented assessment, supporting the systematization of effects, of interspecies extrapolation, and the problems of multiple mixture effects. At the same time, these MBBTs can be valuable as early warning tools to identify areas or sites at risk, they can be valuable as guiding tools in exposure assessment and would lead to the identification and measurement of the relevant compounds (with respect to the effects) or to the recognition of the relevant hazards caused by pollutants or mixtures thereof. Thus, MBBTs not only indicate that certain chemicals are there, but - and this is the major advantage of bioanalytical tools - they indicate that chemicals with a specific mode of toxic action or a specific toxic potential are there. In this way MBBTs bridge exposure and effect assessment and help in a faster identification of the causative agent(s).

Generally, the application of microassays using bacteria, yeast cells, vertebrate cells or invertebrates in environmental assessment has strongly increased in recent years, particularly because of their advantages in terms of costs, speed and need for low sample volume [7, 8, 47, 48, 77, $78,79]$. Also, ethical motivations supported the use of microscaled in vitro assays as alternatives to in vivo animal toxicity tests [80]. However, it should be emphasized that many microassays rely on integrative effect endpoints, such as cytotoxicity, whereas bioanalytical assays - in the sense as defined in this review - rely on mechanistic measurement principles; in other words, the distinctive criterion of bioanalytical tools is not the microscale nature but the mechanism-based analytical detection of contaminants.

With MBBTs one cannot only measure if toxic pollutants are present in unknown mixtures but, depending on the specificity of the assay, also by what mechanism the effect is caused. In order to be able to fully exploit this potential, knowledge of the toxicological mechanisms is a prerequisite. Since ecotoxicological research focussed on mechanistic understanding and application of molecular approaches is in its childhood, much work needs to be done [2]. We expect that the need for powerful, sensitive, specific, fast and cost-efficient bioanalytical tools will increase (e.g. tools that can be used to assess the potential hazard of pollutants present in environmental samples and newly synthesized, pure chemicals). The current and intensively debated problem of environmental pollutants with endocrine-mimicking effects clearly point to that need.

A trend towards the implementation of molecular detection methods in the development of new MBBTs is obvious. Most probably these tools will increase the sensitivity and speed of the measurements. However, without knowing the biological relevance of the response, they will stay rather phenomenological, and will not increase our insight into principles. This insight is urgently needed. The implementation of modern methods from life sciences, such as functional genomics, in ecotoxicology is also required. This will speed up the identification of the key toxicological reactions, the basis for bioanalytical tool development. Furthermore, the reactions are measured in a biological context, thereby increasing the relevance of the response measured. Again, much work needs to be done in this context.

A further promising development for the use of bioanalytical tools for exposure and effect assessment is the incorporation of nanotechnologically based devices, leading to the development of portable instruments, the miniaturized measurement of effects, even in arrays of possible effects or something simple like dipsticks, to be used for the quick assessment of environmental chemical quality.

The potential for using MBBTs in exposure and effect assessment seems very promising and rational. With the 
expected increasing need for assessing the potential ecotoxicological hazards of pollutants and the increasing demand to screen environmental quality and health, these approaches become increasingly attractive. However, the application record of the currently available MBBTs is not so convincing yet. Why is that? Maybe the MBBTs are not as promising as we think (and say) they are. Their advantages, in being more specific, mostly more sensitive, faster, easier to handle, mostly cheaper and less ethically critical than the currently used tests, dominate. It is therefore plausible to assume that the quality of the MBBTs is good and it will be a matter of time before their use will increase. Another possibility for the not so frequent use of the MBBTs might be that the pressure to adopt novel bioanalytical tools is not high enough yet; the routinely used, governmentally accepted test systems remain the preferred ones. Routinely used toxicity test systems and protocols are known and much experience has been gathered in using them. Novel MBBTs might be too specific and too sensitive, causing novel regulatory problems. In addition the year-long practical experience and immense data sets are still missing. Finally, in our experience, we have encountered strong interest in novel MBBTs, up to the point were legal aspects come into play. As long as the currently established tests are the ones that form the basis for legal risk assessment procedures, novel tools will have a problem in becoming routine.

We are convinced, however, that although much needs to be done before MBBTs will and can be fully embedded in toxicological risk assessment and environmental screening programmes, this approach will become increasingly used in environmental hazard assessment. When screening through the current ecotoxicological literature, the percentage of publications using MBBTs is steadily increasing. Changing threats to our environment bring attention to sub-acute effects occurring below the level of acute systemic toxicity and demand the development of assessment tools that are able to detect both the impact of chronic low-dose exposure to complex chemical mixtures and the chemicals within these mixtures being responsible for the effects. Progress in basic research towards the mechanisms underlying the toxicological processes will enable the identification of key reactions and target molecules that can be utilized as bioanalytical recognition elements for rational, targeted environmental assessment.

\section{References}

1. Newman MC (1998) Fundamentals of ecotoxicology. Ann Arbor Press, Chelsea, USA

2. Eggen RIL, Behra R, Escher B, Holm P, Schweigert N (2003) (submitted)

3. Segner H, Braunbeck T (1998) In: Schüürmann G, Markert B (eds) Ecotoxicology. Wiley, New York, pp 521-570

4. Escher BI, Eggen RIL, Schreiber U, Schreiber Z, Vye E, Wisner B, Schwarzenbach RP (2002) Environ Sci Technol 36: 1971-1979

5. Hall JM, Couse JF, Korach KS (2001) J Biol Chem 276: 36869-36872

6. Sherry J (1997) Chemosphere 34:1011-1025
7. Wells PG, Lee K, Blaise C (1997) Microscale testing in aquatic toxicology. CRC Press, Boca Raton, USA

8. Janssen C (1998) In: Schüürmann G, Markert B (eds) Ecotoxicology. Wiley, New York, pp 813-839

9. Harrison RO, Carlson RE (1997) Chemosphere 34:915-928

10. Vo-Dinh T, Cullum B (2000) Fresenius J Anal Chem 366, $540-551$

11. Warsinke A, Benkert A, Scheller FW (2000) Fresenius J Anal Chem 366:622-634

12. Galloway TS, Sanger RC, Smith KL, Readman JW, Ford TE, Depledge MH (2002) Environ Sci Technol 36:2219-2216

13. Roda A, Pasini P, Guardigli M, Baraldini M, Musiani M, Mirasoli M (2000) Fresenius J Anal Chem 366:752-759

14. Gerlach RW, van Emon JM (1997) Chemosphere 35:27272749

15. Yakiuda K, Hemmi A, Ito S, Asano Y (1996) Biosens Bioelectron 11:703-707

16. Sadik OA, Witt DM (1999) Environ Sci Technol 33(17):368A $-374 \mathrm{~A}$

17. Ercegovich CD (1971) Am Chem Soc 55-75

18. Chi Y, Carison PE, Marcus KL, Karu AE (1995) Anal Chem 67:3829-3839

19. Pullen S, Hock B (1995) Anal Lett 28:765-779

20. Karu AE, Goodrow MH, Schmidt DJ, Hammock BD, Bigelow MW (1994) J Agric Food Chem 42:301-309

21. Chakrabati P, Hatchjer EM, Blake RC, Ladd PA, Blake DA (1994) Anal Biochem 217:70-75

22. Fujita M, Ike M, Goda Y, Fujimoto S, Toyoda Y, Miyagawa K (1998) Environ Sci Technol 32:1143-1146

23. Goda Y, Fujimoto S, Toyoda Y, Miyagawa K, Ike M, Fujita M (2000) Water Sci Technol 42:81-88

24. Stanker LH, Watkins B, Rogers N, Vanderlaan M (1987) Toxicol 4:229-243

25. Harrison RO (1994) Abstr pap Am Chem Soc 207:94

26. Harrison RO, Carlson RE (1998) Organohalogen Comp 36: 129-132

27. Sherry J, ApSimon J, Collier L, Wilkinon R, Albro P, Zfghan B (1989) Chemosphere 19:255-261

28. Zajicek JL, Tillitt DE, Schwartz RE, Schmitt CJ, Harrisson RO (2000) Chemosphere 40:539-548

29. Focant JF, Eppe G, de Pauw E (2001) Chemosphere 43:417424

30. Sugawara Y, Saito K, Ogawa M, Kobayashi S, Shan G, Sanborn JR, Hammock BD, Nakazawa H, Matsuki Y (2002) Chemosphere 46:1471-1476

31. Hamers T, Molin KRJ, Koeman JH, Murk AJ (2000) Toxicol Sci 58:60-67

32. Brack W, Paschke A, Segner H, Wennrich R, Schüürmann, G (2000) Chemosphere 40:829-834

33. Hamers T, Smit MGD, Murk AJ, Koeman JH (2001) Chemosphere 45:609-624

34. Thomas P, Smith J (1993) Mar Environ Res 35:147-151

35. Knudsen FR, Pottinger TG(1999) Aquatic Toxicol 44:159-170

36. Hewitt LM, Parrott JL, Wells KL, Calp MK, Diddiscombe S, McMaster ME, Munkittrick KR, van der Kraak G (2000) Environ Sci Technol 34:4327-4334

37. Kloas W, Schrag B, Ehnes C, Segner H (2000) Gen Comp Endocrinol 119:287-299

38. Takeyoshi M, Yamasaki K, Sawaki M, Nkai M, Noda S, Takatsuki M (2002) Toxicol Lett 126:91-98

39. Bauer ERS, Bitsch N, Brunn, Sauerwein H, Meier HHD (2002) Chemosphere 46:1107-1115

40. Seifert M, Wen L, Alberti M, Kausch U, Hock B (2003) Pure Appl Chem (in press)

41. Hock B (2001) Bioresponse-linked instrumental analysis. Teubner Verlag, Suttgart

42. Loo JA (2001) Int J Mass Spectr 36:664-669

43. Köhler S, Belkin S, Schmid RD (2000) Fresenius J Anal Chem 366:769-779

44. Sanderson JT, Aarts JMMJGA, Brouwer A, Froese KL, Denison MS, Giesy JP (1996) Toxicol Appl Pharmacol 137:316325 
45. Murk AJ, Legler J, Denison MS, Giesy JP, Guchte C, Brouwer A (1996) Fund Appl Toxicol 33:149-160

46. Petit F, LeGoff P, Cravedi JP, Valotaire Y, Pakdl F (1997) J Mol Endocrinol 19:321-335

47. Gillesby BE, Zacharewski TR (1998) Environ Toxicol Chem 17:3-14

48. Giesy JP, Hilscherova K, Jones PD, Kannan K, Machala M (2002) Mar Poll Bull 45:3-16

49. D'Souza SF (2001) Biosens Bioelectron 16:337-353

50. El-Fouly MH, Richter CA, Giesy JP, Denison MS (1994) Environ Toxicol Chem 10:1581-1588

51. Garrison PM, Tullis K, Aarts JMMJG, Brouwer A, Giesy JP, Denison MS (1996) Fund Appl Toxicol 30:194-203

52. Hahn ME, Woodward BL, Stegeman JJ, Kennedy SW (1996) Environ Toxicol Chem 15:582-591

53. Kennedy SW, Lorenzen A, Norstrom RJ (1996) Environ Sci Technol 30:706-715

54. Clemons JH, Lee LEJ, Myers CR, Dixon DG, Bols NC (1996) Can J Fish Aquatic Sci 53:1177-1185

55. Till M, Behnisch P, Hagenmaier H, Bock KW, Schrenk D (1997) Environ Health Persp 105:1326-1332

56. Behrens A, Schirmer K, Bols NC, Segner H (2001) Environ Toxicol Chem 20:632-643

57. Richter CA, Tieber VL, Denison MS, Giesy JP (1997) Environ Toxicol Chem 16:543-550

58. Van den Berg M, Birnbaum L, Bosveld ATC, Brunstrom G, Cook P, Feeley M, Giesy JP, Hanberg A, Hasegawa F, Kennedy SW, Kubiak T, Larsen JC, Van Leeuwen FXR, Liem AKD, Nolt C, Peterson RE, Poellinger L, Safe S, Schrenk D, Tillitt D, Tysklind Younes M, Waer F, Zacharewski T (1998) Environ Health Persp 106:775-792

59. Joyeux A, Balaguer P, Germain P, Boussioux AM, Pons M, Nicolas JC (1997) Anal Biochem 249:119-130

60. Hilscherova K, Machala M, Kannan K, Blankeship AL, Giesy JP (2000) Environ Sci Poll Res 7:159-171

61. Huuskonen SE, Tuvikene A, Trapido M, Fent K, Hahn ME (2000) Arch Environ Cont Toxicol 38:59-69

62. Whyte JJ, Karrow NA, Boermans HJ, Dixon DG, Bols NC (2000) Polycyclic Arom Hydrocarbons 18:71-98

63. Legler J, Jonas A, Lahr J, Vethaak D, Brouwer A, Murk AJ (2002) Environ Chem Toxicol 21:473-479
64. Desbrow C, Routledge EJ, Brighty GC, Sumpter JP, Waldock M (1998) Environ Sci Technol 32:1549-1558

65. Brack W, Segner H, Moder M, Schüürmann G (2000) Environ Toxicol Chem 19:2493-2501

66. Villeneuve DL, Blankenship AL (2000) Environ Toxicol Chem 19:2835-2843

67. Schoeters G, Goyvaerts MP, Ooms D, van Cleuvenbergen R (2003) Chemosphere (in press)

68. Aerni HR, Kobler B, Rutishauser BV, Wettstein FE, Fischer R, Giger W, Hungerbühler A, Marazuala MD, Peter A, Schönenberger R, Vögeli C, Suter MJF, Eggen RIL (2003) (submitted)

69. Roy S, Mysior P, Brzezinski R (2002) Chemosphere 48:833842

70. Brack W, Schirmer K (2003) (submitted)

71. Legler J, Broekhof JLM, Brouwer A, Lanser PH, Murk AJ, van der Saag PT, Vethak AD, Wester P, Zivkovic D, van den Burg B (2000) Environ Sci Technol 34:4439-4444

72. Norbergking TJ, Durhan EJ, Ankley GT (1991) Environ Toxicol Chem10:891-900

73. Ankley GT, Burkhard LP (1992) Environ Toxicol Chem $11: 1235-1248$

74. Brack W, Altenburger R, Ensenbach U, Möder M, Segner H, Schüürmann G (1999) Arch Environ Contam Toxicol 37:164174

75. Reemtsma T (2001) Anal Chim 426:279-287

76. Reineke N, Bester K, Hühnerfuss H, Jastorff B, Weigel S (2002) Chemosphere 47:717-723

77. Segner H (1998) In: Braunbeck T, Hinton DE, Streit B (eds) Fish ecotoxicology. Birkhäuser, Basel, pp 1-38

78. Segner H, Braunbeck T (2003) In: Austin B, Mothersill C (eds) In vitro aquatic toxicology. Springer. Berlin Heidelberg New York (in press)

79. Schweigert N, Eggen RIL, Escher BI, Burkhardt-Holm P, Behra R (2002) ALTEX 19:30-37

80. Castano A, Bols NC, Braunbeck T, Dierickx P, Halder M, Isomaa B, Kawahara K, Lee LEJ, Mothersill C, Pärt P, Repetto G, Sintes JR, Rufli H, Smith R, Wood C, Segner H (2003) ATLA (in press) 